- Sodium hypochlorite is a commonly used irrigant in endodontic practice. It has many potential complications ranging from permanent bleaching of clothes to severe soft tissue damage.

- The complications of hypochlorite extrusion beyond the root apex are discussed.

- Guidelines are given for the safe use of hypochlorite solution during endodontic treatment and advice on the appropriate course of action when a hypochlorite complication is suspected.

\title{
Review: the use of sodium hypochlorite in endodontics - potential complications and their management
}

\author{
H. R. Spencer, ${ }^{1}$ V. Ike ${ }^{2}$ and P. A. Brennan ${ }^{3}$
}

\begin{abstract}
Aqueous sodium hypochlorite (bleach) solution is widely used in dental practice during root canal treatment. Although it is generally regarded as being very safe, potentially severe complications can occur when it comes into contact with soft tissue. This paper discusses the use of sodium hypochlorite in dental treatment, reviews the current literature regarding hypochlorite complications, and considers the appropriate management for a dental practitioner when faced with a potentially adverse incident with this agent.
\end{abstract}

\section{INTRODUCTION}

Sodium hypochlorite $(\mathrm{NaOCl})$ was first recognised as an antibacterial agent in 1843 when hand washing with hypochlorite solution between patients produced unusually low rates of infection transmission between patients. It was first recorded as an endodontic irrigant in $1920^{1}$ and is now in routine worldwide use.

Sodium hypochlorite is used as an endodontic irrigant as it is an effective antimicrobial and has tissue-dissolving capabilities. It has low viscosity allowing easy introduction into the canal architecture, an acceptable shelf life, is easily available and inexpensive. The toxicity of its action to vital tissues

\footnotetext{
${ }^{1}$ Associate Specialist in Oral Surgery, ${ }^{2} \mathrm{SHO}$ in Oral and Maxillofacial Surgery, ${ }^{3 *}$ Consultant Maxillofacial Surgeon, Professor of Surgery, Queen Alexandra Hospital, Portsmouth, P06 3LY

*Correspondence to: Professor Peter Brennan Email: peter.brennan@porthosp.nhs.uk
}

and corrosion of metals ${ }^{2}$ are its main disadvantages in dental use. Sodium hypochlorite reacts with fatty acids and amino acids in dental pulp resulting in liquefaction of organic tissue. ${ }^{3}$ There is no universally accepted concentration of sodium hypochlorite for use as an endodontic irrigant. The antibacterial and tissue dissolution action of hypochlorite increases with its concentration, but this is accompanied by an increase in toxicity. Concentrations used vary down from 5.25\% depending on the dilution and storage protocols of individual practitioners. Solution warmers are available to increase the temperature up to $60^{\circ} \mathrm{C}$. Increasing the temperature of a solution of hypochlorite improves the bactericidal and pulp dissolution activity, although the effect of heat transfer to the adjacent tissues is uncertain. ${ }^{4}$

As a bleaching agent, inadvertent spillage of this agent can result in damage to clothing and soft tissues. Inadvertent introduction of sodium hypochlorite beyond the root canal system may result in extensive soft tissue or nerve damage, and even airway compromise. This arti- cle reviews the potential complications that can occur with sodium hypochlorite in clinical practice, discusses measures that can be taken to minimise risk, and provides details of appropriate management in the rare cases of suspected tissue damage.

\section{COMPLICATIONS OF ACCIDENTAL SPILLAGE}

1) Damage to clothing

Accidental spillage of sodium hypochlorite is probably the most common accident to occur during root canal irrigation. Even spillage of minute quantities of this agent on clothing will lead to rapid, irreparable bleaching. The patient should wear a protective plastic bib, and the practitioner should exercise care when transferring syringes filled with hypochlorite to the oral cavity.

\section{2) Eye damage}

Seemingly mild burns with an alkali such as sodium hypochlorite can result in significant injury as the alkali reacts with the lipid in the corneal epithelial cells, forming a soap bubble that 


\begin{tabular}{l}
$\begin{array}{l}\text { Table } 1 \text { Preventive measures that should be } \\
\text { taken to minimise potential complications } \\
\text { with sodium hypochlorite }\end{array}$ \\
\hline - Plastic bib to protect patient's clothing \\
\hline - Provision of protective eye-wear for both \\
patient and operator \\
\hline - The use of a sealed rubber dam for isolation \\
of the tooth under treatment \\
\hline - The use of side exit Luer-Lok needles for \\
root canal irrigation \\
\hline - Irrigation needle a minimum of $2 \mathrm{~mm}$ short \\
of the working length \\
\hline - Avoidance of wedging the needle into the \\
root canal
\end{tabular}

Table 2 Emergency management of accidental hypochlorite damage

Eye injuries

- Irrigate gently with normal saline. If normal saline is insufficient or unavailable, tap water should be used

- Refer for ophthalmology opinion

Skin injuries

- Wash thoroughly and gently with normal saline or tap water

Oral mucosa injuries

- Copious rinsing with water

- Analgesia if required

- If visible tissue damage antibiotics to reduce risk of secondary infection

- If any possibility of ingestion or inhalation refer to emergency department

Inoculation injuries

- Ice/cooling packs to swelling first 24 hours

- Heat packs subsequently

- Analgesia

- Antibiotics to reduce the risk of secondary infection

- Request advice or management from Maxillofacial Unit

- Arrange review if to be managed in dental practice

penetrates the corneal stroma. The alkali moves rapidly to the anterior chamber, making repair difficult. Further degeneration of the tissues within the anterior chamber results in perforation, with endophthalmitis and subsequent loss of the eye. ${ }^{5}$

Ingram recorded a case of accidental spillage of 5.25\% sodium hypochlorite into a patient's eye during endodontic therapy. ${ }^{6}$ The immediate symptoms included instant severe pain and intense burning, profuse watering (epiphora) and erythema. Loss of epithelial cells in the outer corneal layer may occur. There may be blurring of vision and patchy colouration of the cornea. ${ }^{7}$ Immediate ocular irrigation with a large amount of water or sterile saline is required followed by an urgent referral to an ophthalmologist. ${ }^{8}$ The referral should ideally be made immediately by telephone to the nearest eye department. The use of adequate eye protection during endodontic treatment should eliminate the risk of occurrence of this accident, but sterile saline should always be available to irrigate eyes injured with hypochlorite. It has been advised that eyes exposed to undiluted bleach should be irrigated for 15 minutes with a litre of normal saline. ${ }^{9,10}$

\section{3) Damage to skin}

Skin injury with an alkaline substance requires immediate irrigation with water as alkalis combine with proteins or fats in tissue to form soluble protein complexes or soaps. These complexes permit the passage of hydroxyl ions deep into the tissue, thereby limiting their contact with the water dilutant on the skin surface.

Water is the agent of choice for irrigating skin and it should be delivered at low pressure as high pressure may spread the hypochlorite into the patient's or rescuer's eyes. ${ }^{5}$

\section{4) Damage to oral mucosa}

Surface injury is caused by the reaction of alkali with protein and fats as described for eye injuries above. Swallowing of sodium hypochlorite requires the patient to be monitored following immediate treatment. It is worth noting that skin damage can result from secondary contamination.

\section{Allergy to sodium hypochlorite}

The allergic potential of sodium hypochlorite was first reported in 1940 by Sulzberger ${ }^{11}$ and subsequently by Cohen and Burns. ${ }^{12}$ Caliskan et al. presented a case where a 32-year-old female developed rapid onset pain, swelling, difficulty in breathing and subsequently hypotension following application of $0.5 \mathrm{ml}$ of $1 \%$ sodium hypochlorite. ${ }^{13}$ The patient required urgent hospitalisation in the intensive care unit and management with intravenous steroids and antihistamines. A subsequent allergy skin scratch test performed two weeks after the patient was discharged confirmed a highly positive result to sodium hypochlorite. The usefulness of this test in suspected cases of sodium hypochlorite allergy during endodontic treatment has been confirmed by Kaufman and Keila. ${ }^{14}$ Even though allergy to sodium hypochlorite is rare, it is important for clinicians to recognise the symptoms of allergy and possible anaphylaxis. These may include urticaria, oedema, shortness of breath, wheezing (bronchospasm) and hypotension. Urgent referral to a hospital following first aid management is recommended.

\section{COMPLICATIONS ARISING FROM HYPOCHLORITE EXTRUSION BEYOND THE ROOT APEX}

1) Chemical burns and tissue necrosis

When sodium hypochlorite is extruded beyond the root canal into the periradicular tissues, the effect is one of a chemical burn leading to a localised or extensive tissue necrosis. Given the widespread use of hypochlorite, this complication is fortunately very rare indeed. A severe acute inflammatory reaction of the tissues develops. This leads to rapid tissue swelling both intra orally within the surrounding mucosa and extra orally within the skin and subcutaneous tissues. The swelling may be oedematous, haemorrhagic or both, ${ }^{15}$ and may extend beyond the region that might be expected with an acute infection of the affected tooth $^{16,17}$ (Figs 1, 2). Sudden onset of pain is a hallmark of tissue damage, and may occur immediately or be delayed for several minutes or hours. ${ }^{18}$ Involvement of the maxillary sinus will lead to acute sinusitis. ${ }^{19}$ Associated bleeding into the interstitial tissues results in bruising and ecchymosis of the surrounding mucosa and possibly the facial skin (Fig. 3) and may include the formation of a haematoma. ${ }^{15,20} \mathrm{~A}$ necrotic ulceration of the mucosa adjacent to the tooth may occur as a direct result of the chemical burn. ${ }^{21}$ This reaction of the tissues may occur within minutes or may be delayed and appear some hours or days later. $^{20,22}$ If these symptoms develop, urgent telephone referral should be made to the nearest maxillofacial unit. Patients will be assessed by the on call maxillofacial team. Treatment is determined by the extent and rapidity of the soft tissue swelling but may necessitate urgent hospitalisation and administration of intravenous steroids and antibiotics. ${ }^{718}$ Although the evidence for the use of antibiotics in these patients is 
anecdotal, secondary bacterial infection is a distinct possibility in areas of necrotic tissue and therefore they are often prescribed as part of the overall patient management. Surgical drainage or debridement may also be required depending on the extent and character of the tissue swelling and necrosis., ${ }^{78,19}$

\section{2) Neurological complications}

Paraesthesia and anaesthesia affecting the mental, ${ }^{22}$ inferior dental ${ }^{22}$ and infraorbital branches ${ }^{18,22,23}$ of the trigeminal nerve following inadvertent extrusion of sodium hypochlorite beyond the root canals have been described. Normal sensation may take many months to completely resolve..$^{22,23}$

Facial nerve damage was first described by Witton et al. in $2005 .{ }^{18}$ In both cases, the buccal branch of the facial nerve was affected. Both patients exhibited a loss of the naso-labial groove and a down turning of the angle of the mouth. Both patients were reviewed and their motor function was regained after several months. Sensory and motor nerve deficit are not commonly associated with acute dental abscesses. As there is no other current evidence in the literature it is possible that these neurological complications were a direct result of chemical damage by sodium hypochlorite, but further research (including nerve conduction studies) is required.

\section{3) Upper airway obstruction}

The use of sodium hypochlorite for root canal irrigation without adequate isolation of the tooth can lead to leakage of the solution into the oral cavity and ingestion or inhalation by the patient. This could result in throat irritation ${ }^{22}$ and in severe cases, the upper airway could be compromised. Ziegler presented a case of a 15-month-old girl who presented in the accident and emergency unit with acute laryngotracheal bronchitis, stridor and profuse drooling from the mouth as a result of ingestion of a high concentration of household sodium hypochlorite. $^{24}$ A similar clinical presentation might occur with the ingestion of any caustic substance. ${ }^{25}$ Opinion varies as to the best concentration of hypochlorite, with some practitioners using undiluted household bleach. ${ }^{20}$ Fibre optic nasal tracheal intubation followed by surgical decompression has been required to manage airway compromising swelling arising within three hours of accidental exposure to sodium hypochlorite during root canal treatment (Fig. 4). ${ }^{26}$

\section{What can I do to minimise the risk of} hypochlorite complications?

The use of all chemicals or hazardous substances in practice is covered by legislation requiring employers to control exposure to both staff and patients to prevent ill health. The Control of Substances Hazardous to Health Regulations (2002) $(\mathrm{COSHH})^{27}$ requires a practice to prepare plans and procedures to deal with accidents, incidents and emergencies involving hazardous substances and to adequately control exposure.

As has already been stated, these are rare complications, but nonetheless, the risk of hypochlorite-induced damage can be minimised by implementing the measures listed in Table 1 when performing endodontic therapy. If the aqueous sodium hypochlorite is to be diluted for use, eye protection, face mask, gloves and plastic apron should be worn for the procedure. The prepared solution must be stored in a lightproof, non-metallic container that is appropriately labelled.

During treatment the patient's clothing should be protected with a bib that is impermeable to liquid. The patient and clinical team should wear well fitting protective glasses. Rubber dam should be used to isolate the tooth and minor defects in adaptation corrected with a caulking agent to optimise the seal. If the canal is to be irrigated using a needle and syringe, the needle must be side venting. The use of hypodermic (end exiting) needles in root canal irrigation risks accidental inoculation into the soft tissues.

Only Luer-Lok style syringes and needles should be used, as taper seat needles may dislodge in use, with uncontrolled loss of the hypochlorite solution under pressure. ${ }^{29,30}$ The needle should not engage the sides of the canal, but be loosely positioned within the canal. The needle should not reach the apical extent of the prepared canal. ${ }^{30}$ This technique may be facilitated by marking the working length on the needle with a rubber stop (Fig. 5). The irrigant is delivered slowly with minimal pressure to reduce the likelihood of forcing it through the apex. This is most easily achieved by using your index finger rather than
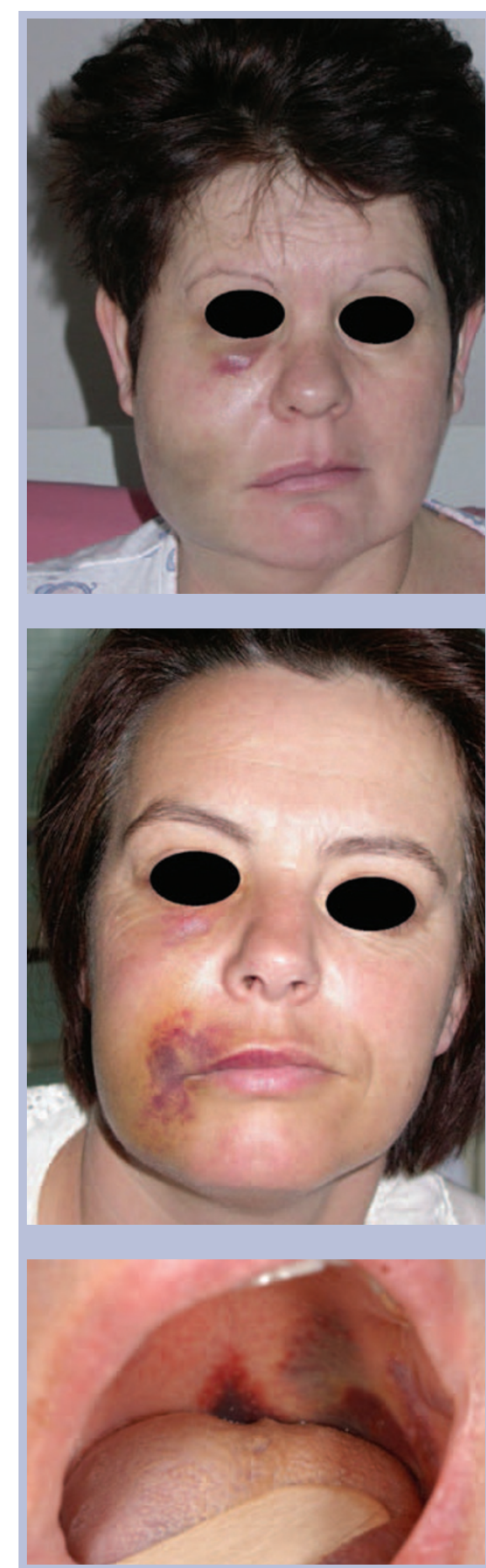

Figs 1-3 Bruising and oedema of three patients who presented with hypochlorite extrusion into the soft tissues

thumb to depress the plunger. ${ }^{30}$ This will reduce the risk to periapical tissues by inadvertent extrusion of irrigant.

Particular care must be taken in immature teeth with open apices to ensure that the irrigant does not go into the apical tissues. Sodium hypochlorite and saline are both recommended for irrigation in immature teeth, however, if hypochlorite is used it has been suggested the final irrigation should be with 


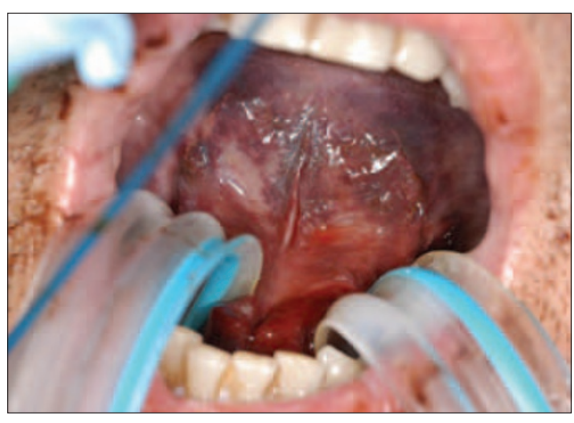

Fig. 4 Upper airway compromise requiring decompression following extrusion of hypochlorite into the soft tissues

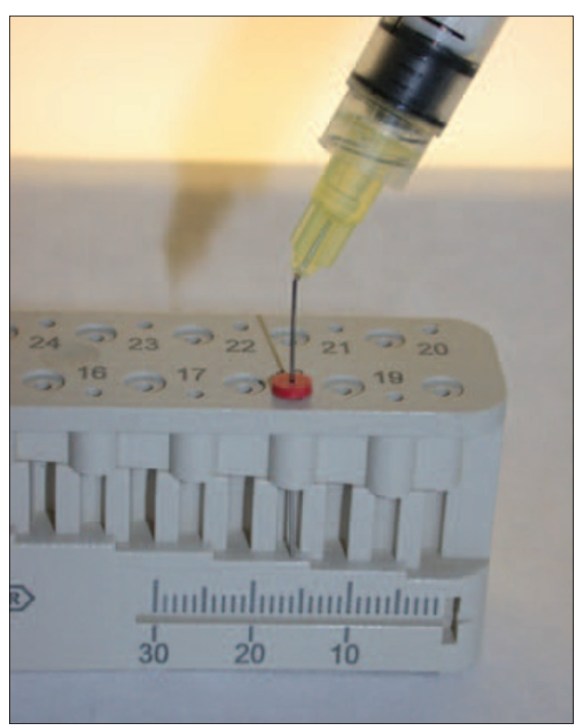

Fig. 5 Placement of rubber stop on irrigation needle

saline to remove any hypochlorite from the canal. ${ }^{31}$

In keeping with the COSHH regulations, ${ }^{27}$ clinicians would also be required to prevent or adequately control exposure to sodium hypochlorite as far as is reasonably practicable. This may include changing the treatment plan to eliminate the need for sodium hypochlorite, using a replacement or using it in a safer form eg a dilute but equally active concentration.

Spangberg and Langeland carried out a series of in vivo and in vitro tests on various potential irrigants. ${ }^{32}$ They found that as well as being highly toxic and irritating, 5\% sodium hypochlorite was considerably stronger than necessary to kill the bacteria in the root canal, while 0.5\% concentration dissolves necrotic tissue but has no effect on Staphylococcus aureus. They therefore recommended the ideal solution to be one that combines maximal antimicrobial effect with minimal toxicity. These results were confirmed by Yesiloy et al., who found that the antimicrobial effects of sodium hypochlorite were much less with concentrations of $2.5 \%$ and lower. ${ }^{33}$ They also found that chlorhexidine gluconate $0.12 \%$ has the equivalent antimicrobial effect to 5.25\% sodium hypochlorite. It has been shown that chlorhexidinetreated root canals are less susceptible to re-infection. ${ }^{34}$ Chlorhexidine is the irrigant of choice in re-treatment cases. ${ }^{30}$ However, sodium hypochlorite remains the most commonly used and recommended endodontic irrigant as it alone combines antimicrobial and tissue dissolving capabilities essential in teeth not previously root filled.

\section{What should I do if I suspect a hypochlorite} complication?

No standard therapy for the management of complications has been documented, probably because these complications are rare and sporadic.

\section{Initial management}

Tissue swelling can potentially be minimised by using cold compression (frozen items wrapped in a towel). If the patient is being treated under local anaesthesia they may not experience pain immediately. Mild to moderate pain may be managed with analgesia such as ibuprofen and paracetamol. ${ }^{8}$ Adult doses of paracetamol $1 \mathrm{~g}$ qds and ibuprofen or ibuprofen $400 \mathrm{mg}$ qds can be used alternately at four hourly intervals if necessary. Oral antibiotics may also be prescribed to minimise the risk of secondary bacterial infection; Amoxicillin $250 \mathrm{mg}$ tds or Metronidazole $200 \mathrm{mg}$ tds in the penicillin allergic patient. It should be emphasised that careful patient record keeping is very important in clinical practice. The precise details of the event should be documented including concentration and volume of the hypochlorite solution involved. The measures employed to minimise risk (eg rubber dam, eye protection, working length measurement) should also be documented. Clinical photographs may also be appropriate to supplement the notes.

Conservative management for hypochlorite complications has been recommended. ${ }^{28}$ While this may be appropriate in patients who develop mild complications, it is not to be universally recommended. Urgent referral is necessary in all cases involving ingestion or inhalation of hypochlorite, as the clinical consequences cannot be predicted from the oropharyngeal symptoms. Maxillofacial advice and assessment is recommended for any suspected hypochlorite complication.

In summary, this review discusses the potential complications that can occur with sodium hypochlorite in endodontic dental practice. Although rare, the recognition and subsequent primary management by the dental practitioner of these complications is essential to ensure best clinical practice.

1. Crane A B. A practicable root canal technique. Philadelphia: Lea \&t Febinger, 1920.

2. O'Hoy PY, Messer H H, Palamara J E. The effect of cleaning procedures on fracture properties and corrosion of NiTi files. Int Endod J 2003; 36: 724-732.

3. Estrela C, Estrela R A C, Barbin E L et al. Mechanism of action of sodium hypochlorite. Braz Dent J 2002; 13: 113-117.

4. Sirtes G, Waltimo T, Schaetzle M et al. The effects of temperature on sodium hypochlorite short term stability, pulp dissolution capacity and antimicrobial efficacy. J Endod 2005; 31: 669-671.

5. Marx, Hockberger, Wallis. Rosen's emergency medicine. 6th edn. pp 931-933. UK: Mosby Elsevier, 2006

6. Ingram TA. Response of the human to accidental exposure to sodium hypochlorite. J Endod 1990; 16: 235-237.

7. Gatot A, Arbelle J, Leiberman A et al. Effects of Sodium hypochlorite on soft tissues after its inadvertent injection beyond the root apex. J Endod 1991; 17: 573-574

8. Hulsmann M, Hahn W. Complications during root canal irrigation - literature review and case reports. Int Endod J 2000; 33: 186-193.

9. Rutala W, Weber D J. Uses of inorganic hypochlorite (Bleach) in health-care facilities. Clinical Microbiology Reviews 1997; 10: 597-610.

10. Skinner D, Swain A, Peyton R et al. Cambridge textbook of emergency medicine. pp 737-738. UK: Cambridge University Press, 1997.

11. Sulzberger M B. Dermatologic allergy: an introduc tion in the form of a series of lectures. Springfield, IL, USA: Charles C. Thomas, 1940.

12. Cohen $S$, Burns R. Pathways of the pulp. $3^{\text {rd }}$ edn. pp 441-442. St Louis, MO, USA: CV Mosby, 1984.

13. Caliskan M K, Turkun M, Alper S. Allergy to sodium hypochlorite during root canal therapy: a case report. Int Endod J 1994; 27: 163-167.

14. Kaufman A Y, Keila S. Hypersensitivity to sodium hypochlorite. J Endod 1989; 15: 224-226.

15. Mehra P, Clancy C, Wu J. Formation of a facial hematoma during endodontic therapy. J Am Dent Assoc 2000; 131: 67-71.

16. Sabala G L, Powell S E. Sodium hypochlorite injection into periapical tissues. J Endod 1989; 15: 490-492.

17. Joffe E. Complication during root canal therapy following accidental extrusion of sodium hypochlorite through the apical foramen. Gen Dent 1991; 460-461.

18. Witton $\mathrm{R}$, Henthorn $\mathrm{K}$, Ethunandan $\mathrm{M}$ et al. Neurological complications following extrusion of sodium hypochlorite solution during root canal treatment. Int Endod J 2005; 38: 843-848.

19. Kavanagh $C$ P, Taylor J. Inadvertent injection of sodium hypochlorite into the maxillary sinus. BrDent J 1998; 185: 336-337.

20. Gernhardt C R, Eppendorf K, Kozlowski A et al. Toxicity of sodium hypochlorite used as an endodontic irrigant. Int Dent J 2004; 37: 272-280.

21. Reeh E S, Messer H H. Long-term paraesthesia following inadvertent forcing of sodium hypochlorite through perforation in maxillary incisor. Endod 
Dent Traumatol 1989; 5: 200-203.

22. Becking A G. Complications in the use of sodium hypochlorite during endodontic treatment. Oral Surg Oral Med Oral Path 1991; 71: 346-348.

23. Serper A, Ozbek M, Calt S. Accidental sodium hypochlorite-induced skin injury during endodontic treatment. J Endod 2004; 30: 180-181.

24. Ziegler D S. Upper airway obstruction induced by a caustic substance found responsive to nebulised adrenalin. J Paed Child Health 2001; 37: 524-525.

25. Moulin D, Bertrand J M, Buts J P et al. Upper airway lesions in children after accidental ingestion of caustic substances. J Pediatr 1984; 106: 408-410.

26. Bowden J R, Ethuandan M, Brennan P A. Life threatening airway obstruction secondary to hypochlorite extrusion during root canal treatment. Oral Surg Oral Med Oral Pathol Oral Radiol Oral Endod 2006; 101: 402-404.

27. The Control of Substances Hazardous to Health Regulations. (COSHH) 2002.

28. Hales J J, Jackson C R, Everett A P et al. Treatment protocol for the management of a sodium hypochlorite accident during endodontic therapy. Gen Dent 2001; 49: 278-281.

29. Clarkson R M, Moule A J. Sodium hypochlorite and its use as an endodontic irrigant. Aust Dent J 1998; 43: 250-256.

30. Manogue $M$, Patel $S$, Walker R. The principles of endodontics. pp 138-139. Oxford: Oxford University Press, 2005

31. Mackie I C. UK National Clinical Guidelines in
Paediatric Dentistry. Management and root canal treatment of non-vital immature permanent incisor teeth. Faculty of Dental Surgery, Royal College of Surgeons. Int J Paediatr Dent 1998; 8: 289-293.

32. Spangberg $L$, Langeland K. Biological effect of dental materials 1. Toxicity of root canal filling materials on HeLa cells in vitro. Oral Surg Oral Med Oral Pathol 1973; 35: 402-414.

33. Yesilsoy $C$, Whitaker E, Cleveland D et al. Antimicrobial and toxic effects of established and potential root canal irrigants. J Endodont 1995; 21: 513-515.

34. Heling I, Sommer M, Steinberg D et al. Microbiological evaluation of the efficacy of chlorhexidine in a sustained-release device for dentine sterilisation. Int Endod J 1992; 25: 15-19. 